\title{
Nigrostriatal denervation changes the effect of cannabinoids on subthalamic neuronal activity in rats
}

\author{
Teresa Morera-Herreras • José Ángel Ruiz-Ortega • \\ Gurutz Linazasoro $\cdot$ Luisa Ugedo
}

Received: 19 July 2010 /Accepted: 30 September 2010 /Published online: 20 October 2010

(C) The Author(s) 2010. This article is published with open access at Springerlink.com

\begin{abstract}
Rationale: It is known that dopaminergic cell loss leads to increased endogenous cannabinoid levels and CB1 receptor density.

Objective: The aim of this study was to evaluate the influence of dopaminergic cell loss, induced by injection of 6-hydroxydopamine, on the effects exerted by cannabinoid agonists on neuron activity in the subthalamic nucleus (STN) of anesthetized rats.

Results: We have previously shown that $\Delta^{9}$-tetrahydrocannabinol $\left(\Delta^{9}-\mathrm{THC}\right)$ and anandamide induce both stimulation and inhibition of STN neuron activity and that endocannabinoids mediate tonic control of STN activity. Here, we show that in intact rats, the cannabinoid agonist WIN 55,212-2 stimulated all recorded STN neurons. Conversely, after dopaminergic depletion, WIN 55,212-2, $\Delta^{9}$-THC, or anandamide inhibited the STN firing rate without altering its discharge pattern, and stimulatory effects were not observed. Moreover, anandamide exerted a more intense inhibitory effect in lesioned rats in comparison to control rats. Conclusions: Cannabinoids induce different effects on the STN depending on the integrity of the nigrostriatal pathway. These findings advance our understanding of the role of cannabinoids in diseases involving dopamine deficits.
\end{abstract}

Teresa Morera-Herreras and José Ángel Ruiz-Ortega contributed equally to this study.

T. Morera-Herreras · J. Á. Ruiz-Ortega • L. Ugedo $(\bowtie)$

Department of Pharmacology, Faculty of Medicine,

University of the Basque Country,

48940 Leioa, Vizcaya, Spain

e-mail: luisa.ugedo@ehu.es

G. Linazasoro

Centro Investigación Parkinson, Policlínica Gipuzkoa,

San Sebastián, Gipuzkoa, Spain
Keywords Cannabinoid · Parkinson's disease · 6-Hydroxydopamine $\cdot$ Basal ganglia $\cdot$ Electrophysiology

\section{Introduction}

Parkinson's disease (PD) is a neurological disorder characterized by a progressive degeneration of nigral dopaminergic neurons projecting to the striatum (reviewed in Blandini et al. 2000). Numerous studies have suggested that altered neuronal output from the subthalamic nucleus (STN) in the dopamine-deficient state is central to the pathophysiology of PD (Benazzouz et al. 2000). An elevated discharge rate and a preponderant bursting pattern of STN neurons have been reported in experimental models of PD (Bergman et al. 1994; Hassani et al. 1996; Vila et al. 2000; Magill et al. 2001; Breit et al. 2007); indeed, some STN cells have been found to exhibit a rhythmic activity which is highly correlated with limb tremor in Parkinsonian patients (Levy et al. 2000; Magariños-Ascone et al. 2000). The importance of the STN in the etiopathology of movement disorders is also evidenced by the effective therapeutic effects of surgical lesions, high frequency electrical stimulation, or pharmacological blockade in rats (Piallat et al. 1999; Burbaud et al. 1995), in Parkinsonian monkeys and in PD patients (Limousin et al. 1995), where decreasing the activity of the STN ameliorates the major motor symptoms and reverses some of the electrophysiological and metabolic consequences of dopamine depletion (Hamani et al. 2004).

The endocannabinoid system appears to be implicated in the central regulation of motor functions. CB1 receptors and endocannabinoids are abundant in the basal ganglia, which comprise areas known to be involved in motor control (Julian et al. 2003; Bisogno et al. 1999; Hohmann and Herkenham 2000; Mackie 2005). Indeed, endogenous, 
plant-derived, and synthetic cannabinoids have potent, mostly inhibitory effects on motor activity (Crawley et al. 1993; Fride and Mechoulam 1993; Smith et al. 1994; Romero et al. 2002). On the other hand, it has been found that $\mathrm{CB} 1$ receptor binding and endocannabinoid levels are increased in the basal ganglia, both in experimental models of parkinsonism (Romero et al. 2000; Gubellini et al. 2002; Maccarrone et al. 2003; Gonzalez et al. 2006) and in Parkinsonian patients (Lastres-Becker et al. 2001; Pisani et al. 2005). However, the issue is far from clear as other authors have also reported no changes (Herkenham et al. 1991), reduced levels (Silverdale et al. 2001), or dependency of levels on chronic L-dopa co-treatment (Zeng et al. 1999).

Therefore, it has been suggested that cannabinoid modulation may represent an effective tool to be included in novel therapeutic treatments of motor disturbances (Consroe 1998; Di Marzo et al. 2004; Brotchie 2003; Pacher et al. 2006). Thus, the aim of the present study was to characterize STN neuron activity and to examine the effect of the cannabinoids $\Delta^{9}$-tetrahydrocannabinol $\left(\Delta^{9}-\mathrm{THC}\right)$, anandamide, and of the synthetic cannabinoid receptor agonist WIN 55,212-2, in 6-hydroxydopamine (6-OHDA)-lesioned rats which, due to dopamine depletion, represent a model of PD.

\section{Materials and methods}

Male albino Sprague-Dawley rats weighing 250-350 g were housed under controlled environmental conditions $\left(22^{\circ} \mathrm{C}\right.$ and a $12-\mathrm{h}$ light/dark cycle) with free access to food and water. All experiments complied with international guidelines concerning the ethical use of animals specified in the European Communities Council Directive of 24 November 1986 (86/609/EEC).

\section{6-OHDA-induced lesion}

Animals were anesthetized with chloral hydrate $(400 \mathrm{mg} /$ $\mathrm{kg}$, i.p.) and were placed in a stereotaxic frame. Thirty minutes before stereotaxic lesioning, rats were pretreated with desipramine $(25 \mathrm{mg} / \mathrm{kg}$, i.p.) in order to protect noradrenergic terminals from 6-OHDA toxicity and with pargyline $(50 \mathrm{mg} / \mathrm{kg}$, i.p.) to inhibit monoamine oxidases. 6-OHDA was unilaterally injected into the right nigrostriatal pathway at a site just anterior to the substantia nigra and dorsal to the medial forebrain bundle (coordinates, $4.4 \mathrm{~mm}$ anterior to the lamboid suture, $1.2 \mathrm{~mm}$ lateral to the midline suture, and $8.2 \mathrm{~mm}$ ventral to the cortical surface (Paxinos and Watson 1986)). Each rat received an injection of $4 \mu \mathrm{l}$ of 6-OHDA $(2 \mu \mathrm{g} / \mu \mathrm{l}$ in saline containing $0.02 \%$ ascorbic acid). Electrophysiological experiments were performed 4 weeks after the lesion. Lesion severity was evaluated after all experimental procedures by immunohistochemistry.
Electrophysiology

Rats were anesthetized with urethane $(1.2 \mathrm{~g} / \mathrm{kg}$, i.p.), a cannula was inserted into the trachea, and the right jugular vein was cannulated for additional drug administration. Animal body temperature was maintained at $\sim 37^{\circ} \mathrm{C}$ for the entire duration of the experiment by means of a heating pad connected to a rectal probe. The rat was placed in a stereotaxic frame with its head secured in a horizontal orientation. The skull was exposed, and a 3-mm burr hole was drilled over the right STN. For intracerebroventricular (i.c. v.) drug administration, a 23-gauge steel catheter was inserted into the right lateral ventricle, $1.0 \mathrm{~mm}$ caudally and $1.3 \mathrm{~mm}$ laterally to Bregma, at a depth of $4-5 \mathrm{~mm}$ from the skull surface, and fixed with dental cement. The intraventricular position of the catheter was controlled by inspection of the level of an air bubble in a plastic tube connected to the cannula.

The recording electrode, consisting of an Omegadot single glass micropipette, pulled with an electrode puller (Narishige Scientific Instrument Lab., PE-2, Japan), was broken back to a tip diameter of 1-2.5 $\mu \mathrm{m}$ under a light microscope and filled with 2\% Pontamine Sky Blue in $0.5 \%$ sodium acetate. The electrode was placed $3.2-3.5 \mathrm{~mm}$ posterior to Bregma, 2.2-2.7 mm lateral to midline, and 7$8 \mathrm{~mm}$ ventral to the dura mater (Paxinos and Watson 1986). The extracellular signal from the electrode was amplified with a high-input impedance amplifier, and then monitored on an oscilloscope and on an audio monitor. All recorded STN neurons exhibited a biphasic waveform and a pulse width of 1.0 to $1.5 \mathrm{~ms}$ (as described by Hollerman and Grace 1992). Neuronal spikes were digitized using computer software (CED micro 1401 interface and Spike2 software, Cambridge Electronic Design, UK). The basal firing rate was recorded for 3-5 min. Only one STN cell was pharmacologically studied in each animal.

Data regarding the firing patterns of the discriminated STN neurons were analyzed off-line using the Spike2 software, and the following parameters were calculated: firing rate and coefficient of variation (the latter is a measure of firing regularity and is defined as the percentage ratio of the standard deviation to the mean interval histogram). Using the NeuronFit program (NorayBio Informatics), three different firing patterns could be distinguished according to the method of Kaneoke and Vitek (1996), based on the concept of density distribution and on a statistically rigorous definition of the firing pattern: (1) a tonic firing pattern characterized by a symmetrical density distribution histogram, (2) a random firing pattern characterized by a Poisson distribution, and (3) a bursting firing pattern characterized by a distribution histogram which is significantly different $(p<0.05)$ to a Poisson distribution, presenting a significantly positive skewness $(p<0.05)$ of the density distribution histogram 
and a minimum of four spikes per burst. The analyzed spike-trains lasted more than $120 \mathrm{~s}$ and contained at least 300 spikes.

Experimental data were analyzed using GraphPad Prism software (v. 4.0, GraphPad Software, Inc). Data were reported in terms of mean \pm SEM. Statistical significance was assessed by the paired Student's $t$ test for firing rate and coefficient of variation, to compare basal parameters before and after drug administration, or by the one-way repeated measures analysis of variance (ANOVA), followed by the Newman-Keuls test for the effects of the drugs on STN neurons. To compare the effects of $\Delta^{9}$-THC or anandamide in intact and lesioned groups, a two-way repeated measures ANOVA was used. Firing patterns were compared using the Chi-squared $\left(\chi^{2}\right)$ test. The level of statistical significance was considered to be $p<0.05$.

\section{Histological verifications}

Upon concluding experiments, a 5- $\mu \mathrm{A}$ cathodal current was passed through the recording electrode, thereby depositing a discrete spot of Pontamine Sky Blue at the recording site. Rats were heavily anesthetized and perfused transcardially with phosphate buffer saline (PBS) followed by $4-5 \%$ formaldehyde in PBS. The brains were removed and then cryoprotected in $20 \%$ sucrose in PBS before being frozen at $-80^{\circ} \mathrm{C}$. Coronal sections $(50 \mu \mathrm{m})$ were cut using a cryotome through the striatum, the STN, and the mesencephalon.

All sections containing the STN were subsequently stained with Neutral Red to determine the location of Pontamine Sky Blue dots, and only recordings from rats showing this mark in the STN were further considered. Another series of brain sections was used for free-floating immunohistochemistry of tyrosine hydroxylase $(\mathrm{TH})$ to examine the effect of dopaminergic denervation on the striatum and the substantia nigra pars compacta $(\mathrm{SNpc})$ as described by Bilbao et al. (2006). Slices were incubated in mouse anti-TH antibody, which was subsequently detected using a biotinylated horse anti-mouse antiserum. Both immunoreagents were diluted in PBS. Secondary antibodies were labeled with peroxidase using an $\mathrm{ABC}$ kit (PK 6100, Vector, Burlingame, CA, USA). The presence of bound peroxidase was finally manifested using a commercial kit (Vector VIP ${ }^{\circledR}$, SK 4600, Vector, Burlingame, CA, USA). Subsequently, sections were rinsed, mounted, dehydrated, and coverslipped. The extent of the lesion was verified by the density of striatal dopaminergic innervation based on TH-immunoreactivity. Images of three striatal sections were captured using a digital camera. These images were taken rostrocaudally, and mean optical density (OD) was measured using the NIH image analysis software, ImageJ. For each slide, the whole striatum was delimited, and its optical TH-immunoreactivity density was expressed as a percentage of that of the contralateral intact side with the background in the cortex set as $0 \%$ and the contralateral intact striatum set as $100 \%$.

\section{Drugs}

Anandamide ( $N$-(2-hydroxyethyl)-5Z,8Z,11Z,14Z-eicosatetraenamide) was obtained from Tocris (UK). Delta-9tetrahydrocannabinol $\left(\Delta^{9}\right.$-THC) was a generous gift from GW Pharmaceuticals Ltd. (Salisbury, UK) and rimonabant ([N-piperidino-5(4-chlorophenyl)-1-(2,4-dichlorophenyl)-4methylpyrazolel -carboxamide) from Sanofi-Synthelabo S. A. (France). WIN 55,212-2, 6-OHDA, desipramine, pargyline, chloral hydrate, and urethane were obtained from Sigma (Madrid, Spain). Anandamide was dissolved in Tocrisolve ${ }^{\mathrm{TM}} 100 ; \Delta^{9}$-THC in ethanol solution; WIN 55,212-2 and rimonabant in 1:1:18 cremophor/ethanol/saline solution; 6-OHDA in distilled water containing $1 \mathrm{mg} / \mathrm{ml}$ ascorbate and chloral hydrate; and urethane, desipramine, and pargyline were prepared in $0.9 \%$ saline. Drugs were prepared on the day of the experiment.

\section{Results}

Firing properties of STN neurons in intact and 6-OHDA-lesioned rats

All recorded neurons exhibited the typical electrophysiological characteristics of STN neurons, including a biphasic waveform and a duration of 1.0-1.5 ms. The mean basal firing rate of STN neurons in 6-OHDA-lesioned rats was significantly higher than that found in intact rats $(14.0 \pm 1.2$ vs. $7.1 \pm$ $0.5 \mathrm{~Hz}, n=21$ and $n=60$, respectively, $p<0.0001$, Student's $t$-test; Fig. 1a, d). The coefficient of variation also increased following lesion $(83.5 \pm 10.6$ vs. $60.6 \pm 3.2, p<0.01$, Student's $t$ test; Fig. 1b). Consistently, STN neurons in lesioned rats exhibited more bursting discharge than those in intact rats $\left(\chi^{2}=11.58, d f=2, p<0.01\right.$; Fig. $\left.1 \mathrm{c}\right)$. Thus, in intact rats, $71 \%$ of STN neurons exhibited a tonic-firing pattern, $23 \%$ a bursting pattern, and $6 \%$ a random pattern. In contrast, in lesioned rats, $36 \%$ of STN neurons exhibited a tonic-firing pattern, while $64 \%$ presented a bursting firing pattern. These observed changes are consistent with the generally accepted idea that the STN is hyperactive in the Parkinsonian state (Bergman et al. 1994; Hassani et al. 1996; Vila et al. 2000; Ni et al. 2001; Magill et al. 2001).

Effect of WIN 55,212-2 on STN neurons in intact and 6-OHDA-lesioned rats

We next studied the effect of the synthetic cannabinoid agonist WIN 55,212-2 (31.25-250 $\mu \mathrm{g} / \mathrm{kg}$, i.v., doubling 

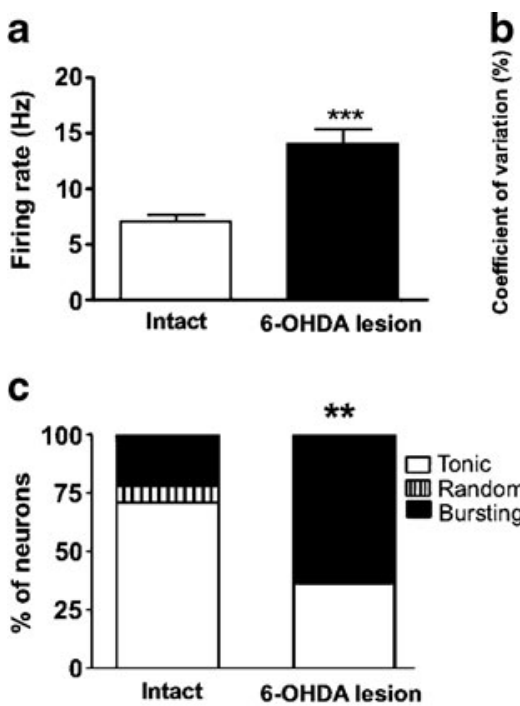

Fig. 1 Histograms illustrating the mean firing rate (a) and mean coefficient of variation (percent) (b) of STN neurons recorded in intact (white square) and 6-OHDA-lesioned (black square) rats; $* * p<0.01$; $* * * p<0.001$ vs. corresponding basal value (Student's $t$ test). Distribution of firing patterns (c) of STN neurons in intact and lesioned rats;

doses) on the electrical activity of STN neurons in intact and lesioned rats (one cell per rat). In intact rats, WIN $55,212-2$ increased the firing rate of STN neurons (maximal effect, $83 \pm 27 \% ; F_{4,39}=27.86, p<0.0001$, one-way repeated measures ANOVA; $n=8$; Fig. $2 \mathrm{a}, \mathrm{c})$. This agonist reduced the coefficient of variation (maximal effect, $26 \pm 8 \% ; F_{4,39}=$ $3,10, p<0.05$, one-way repeated measures ANOVA; Fig. 2d), and firing was essentially of the bursting discharge type (relative amount of neurons exhibiting bursting pattern significantly increased to $100 \% ; \chi^{2}=4.29, d f=1, p<0.05$ ).

In contrast, in lesioned rats, WIN 55,212-2 reduced the firing rate of STN neurons (maximal effect, $51 \pm 13 \%$; $F_{3,19}=5.89, p<0.01$, one-way repeated measures ANOVA; $n=8$; Fig. $2 \mathrm{~b}, \mathrm{c})$, whereas the firing pattern and firing regularity were unaltered $\left(p>0.05, \chi^{2}\right.$ test and one-way repeated measures ANOVA, respectively; Fig. 2d).

As shown in Fig. 2a, b, the effects produced by WIN $55,212-2$ in intact and lesioned rats were reversed by the CB1 antagonist rimonabant $(2,000 \mu \mathrm{g} / \mathrm{kg}$, i.v.). Firing rates before and after rimonabant were $8.08 \pm 2.41$ and $5.26 \pm$ 0.87 spikes/s (paired $t$ test, $p>0.05, n=3$ ) and $11.52 \pm 2.15$ and $9.09 \pm 2.04$ spikes $/ \mathrm{s}$ (paired $t$ test, $p>0.05, n=3$ ), respectively).

Effect of $\Delta^{9}$-THC and anandamide on STN neurons in 6-OHDA-lesioned rats

We next examined the effects of the natural cannabinoid $\Delta^{9}$ THC and the endocannabinoid anandamide on STN neurons in 6-OHDA-lesioned rats. As we have previously shown (Morera-Herreras et al. 2010a, b), administration of $\Delta^{9}$-THC

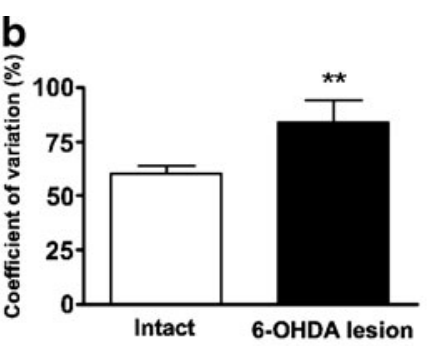

d

Intact rats

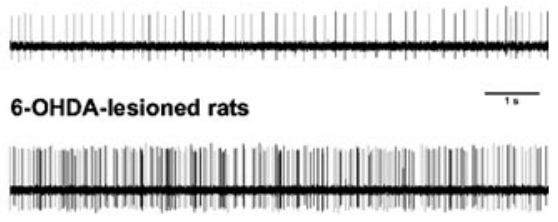

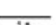

$* * p<0.01$ vs. intact group (Chi-squared $\left(\chi^{2}\right)$ test). d Samples of spontaneous spiking activity recorded in the STN of an intact (top) and a lesioned rat (bottom). Vertical lines represent spike events. Note the increase in the basal firing rate as well as in the bursting discharge in lesioned rats

(250-2,000 $\mu \mathrm{g} / \mathrm{kg}$, i.v.) or anandamide $(50,100$, and $150 \mu \mathrm{g}$, i.c.v.) induced two opposite effects on STN neuron activity in intact rats (Fig. 3). On the one hand, $\Delta^{9}$-THC increased the firing rate (maximal effect, $102 \pm 35 \%, F_{4,49}=13.74$, $p<0.0001$, one-way repeated measures ANOVA; $n=10$ ), the regularity (the coefficient of variation decreased; maximal effect, $31 \pm 6 \%, F_{4,49}=7.72, p<0.0001$, one-way repeated measures ANOVA; $n=10$ ), and the burst firing of STN neurons. On the other hand, $\Delta^{9}$-THC induced a decrease in the basal firing rate (maximal effect, $64 \pm 5 \%$, $F_{4,24}=4.91, p<0.01$, one-way repeated measures ANOVA; $n=5)$ and in the regularity of neuron activity, i.e., the coefficient of variation increased (maximal effect, $101 \pm$ $35 \%, F_{4,24}=4.77, p<0.01$, one-way repeated measures ANOVA; $n=10$ ), but without altering the firing pattern (Fig. 3a, b). Similarly, anandamide induced an increase in the firing rate (maximal effect, $32 \pm 8 \%, F_{3,19}=13.59, p<0.0001$, one-way repeated measures ANOVA; $n=8$ ) and in burst firing, but not in the regularity of neuron activity (the coefficient of variation was unaltered; maximal effect, $2 \pm$ $16 \%, F_{3,19}=0.51, p>0.05$, one-way repeated measures ANOVA; $n=8)$. Anandamide also induced a decrease in the basal firing rate (maximal effect, $31 \pm 5 \%, F_{3,231}=30,15$, $p<0.0001$, one-way repeated measures ANOVA; $n=8$ ) and in the regularity of neuron activity (the coefficient of variation increased; maximal effect, $49 \pm 205 \%, F_{3,31}=4.53$, $p<0.05$, one-way repeated measures ANOVA; $n=8$ ), but without altering the firing pattern (Fig. 3c, d).

However, after 6-OHDA-lesion, $\Delta^{9}$-THC administration induced a decrease in the basal firing rate of all STN neurons recorded (maximal effect, $57 \pm 13 \% ; F_{4,44}=9.38$, 
Fig. 2 Representative firing rate histograms illustrating the effect of intravenous (i.v.) administration of cumulative doses of WIN $55,212-2(31.25-250 \mu \mathrm{g} / \mathrm{kg}$, i.v. doubling doses) on STN neuronal activity in intact (a) and 6-OHDA-lesioned rats (b). Both stimulatory and inhibitory effects were reversed by administration of the CB1 receptor antagonist rimonabant $(250-2,000 \mu \mathrm{g} / \mathrm{kg}$, i.v.). c The mean firing rate and (d) the mean value of the coefficient of variation of STN neurons following WIN 55,212-2 administration $(31.25-250 \mu \mathrm{g} / \mathrm{kg}$, i.v., doubling doses) in intact (white circle; $n=8)$ and lesioned rats (black circle; $n=8$ ). Data are expressed as mean $\pm \mathrm{SEM} ;{ }^{*} p<$ $0.05 ; * * p<0.01 ; * * * p<0.001$ vs. corresponding basal value (one-way repeated measures ANOVA followed by the Student-Newman-Keuls test)

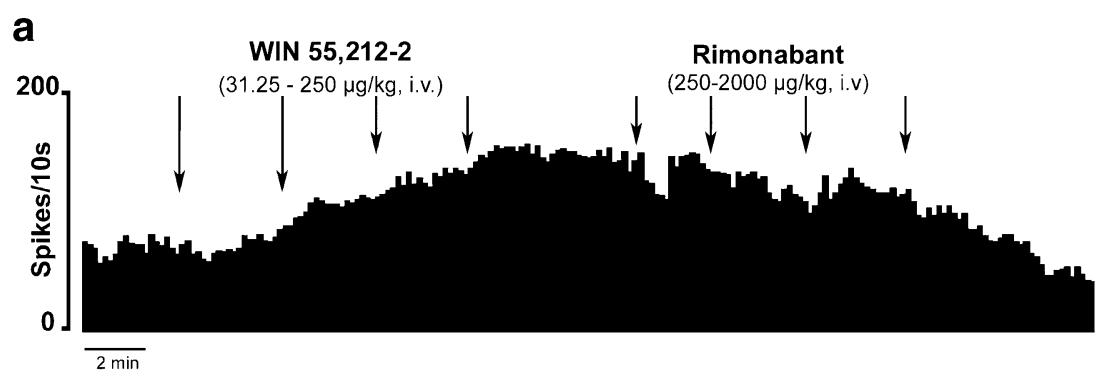

b

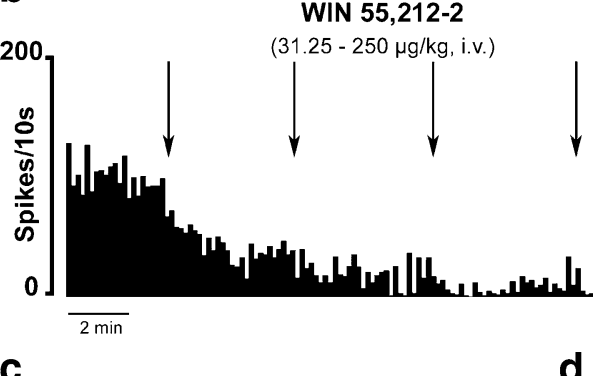

Rimonabant

$(2000 \mu \mathrm{g} / \mathrm{kg}$, i.v)

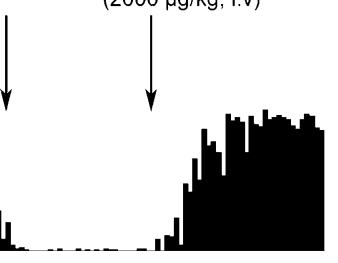

C

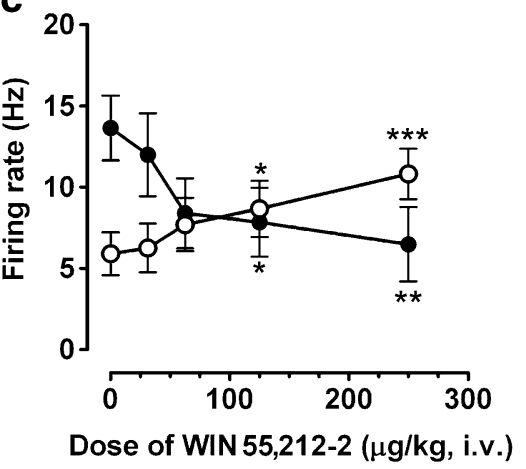

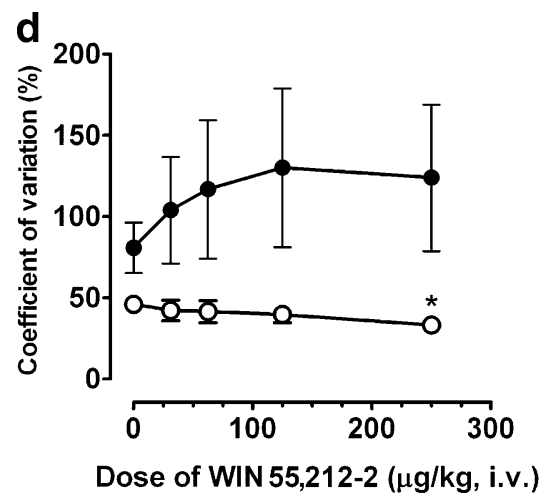

$p<0.0001$, one-way repeated measures ANOVA; $n=9$; Fig. 3a), whereas the firing pattern and the regularity of neuron firing remained unaltered $\left(p>0.05, \chi^{2}\right.$ test and oneway repeated measures ANOVA, respectively; Fig. 3b). No difference in this inhibitory effect was observed between the intact and lesioned groups $\left(F_{1,59}=0.20, p=0.66\right.$, two-way ANOVA; Fig. 3a). Similarly, anandamide reduced the firing rate of all STN neurons recorded (maximal effect, $84 \pm 10 \%$; $F_{3,19}=9.55, p<0.01$, one-way repeated measures ANOVA; $n=5$; Fig. $3 \mathrm{c}$ ), whereas the firing pattern and the regularity of neuron firing were unaltered $\left(p>0.05, \chi^{2}\right.$ test and one-way repeated measures ANOVA, respectively; Fig. 3d). Moreover, in this case, the inhibitory effect induced by anandamide in lesioned rats was significantly higher than that observed in the intact group (two-way ANOVA, $F_{1,41}=$ 73.98, $p<0.0001$; Fig. 3c).

In all recorded neurons, the $\mathrm{CB} 1$ receptor antagonist rimonabant $(2 \mathrm{mg} / \mathrm{kg}$, i.v.) restored the firing rates to basal values. Thus, the firing rates before and after rimonabant were $14.91 \pm 1.83$ and $15.64 \pm 3.04$ spikes/s (paired $t$ test, $p>0.05$, $n=7$ ) and $14.32 \pm 2.62$ and $11.19 \pm 1.89$ spikes/s (paired $t$ test, $p>0.05, n=8$ ) for neurons in lesioned rats in which $\Delta^{9}$-THC and anandamide effects were studied, respectively.
Recording site and tyrosine hydroxylase immunostaining

After the electrophysiological experiments had been carried out, Pontamine Sky Blue dots were localized in Neutral Red stained STN sections, revealing that all recorded neurons from 6-OHDA-lesioned rats and those that were recorded before and after WIN 55,212-2 administration to intact rats were located quite homogeneously over the entire STN (Fig. 4). Conversely, as we have previously shown (Morera-Herreras et al. 2010a, b), neurons inhibited by $\Delta^{9}$-THC or anandamide are predominantly located in the dorsolateral portion of the rostral STN, whereas stimulated neurons are located in the ventromedial portion of the caudal STN.

The effectiveness of dopaminergic depletion by means of 6-OHDA lesion was verified by TH immunohistochemistry. All 6-OHDA lesioned animals included in the study showed $>95 \%$ reduction (remaining dopaminergic fibers $2.9 \pm 0.5 \%$ ) in $\mathrm{TH}$-fiber density in the striatum on the side ipsilateral to the lesion (Fig. 5). The precision of this method to quantify the degree of the lesion is confirmed by the linear relationship between the number of $\mathrm{TH}$ immunoreactive neurons in the SNpc and optical density in the striatum (Bilbao et al. 2006). Thus, further cell 

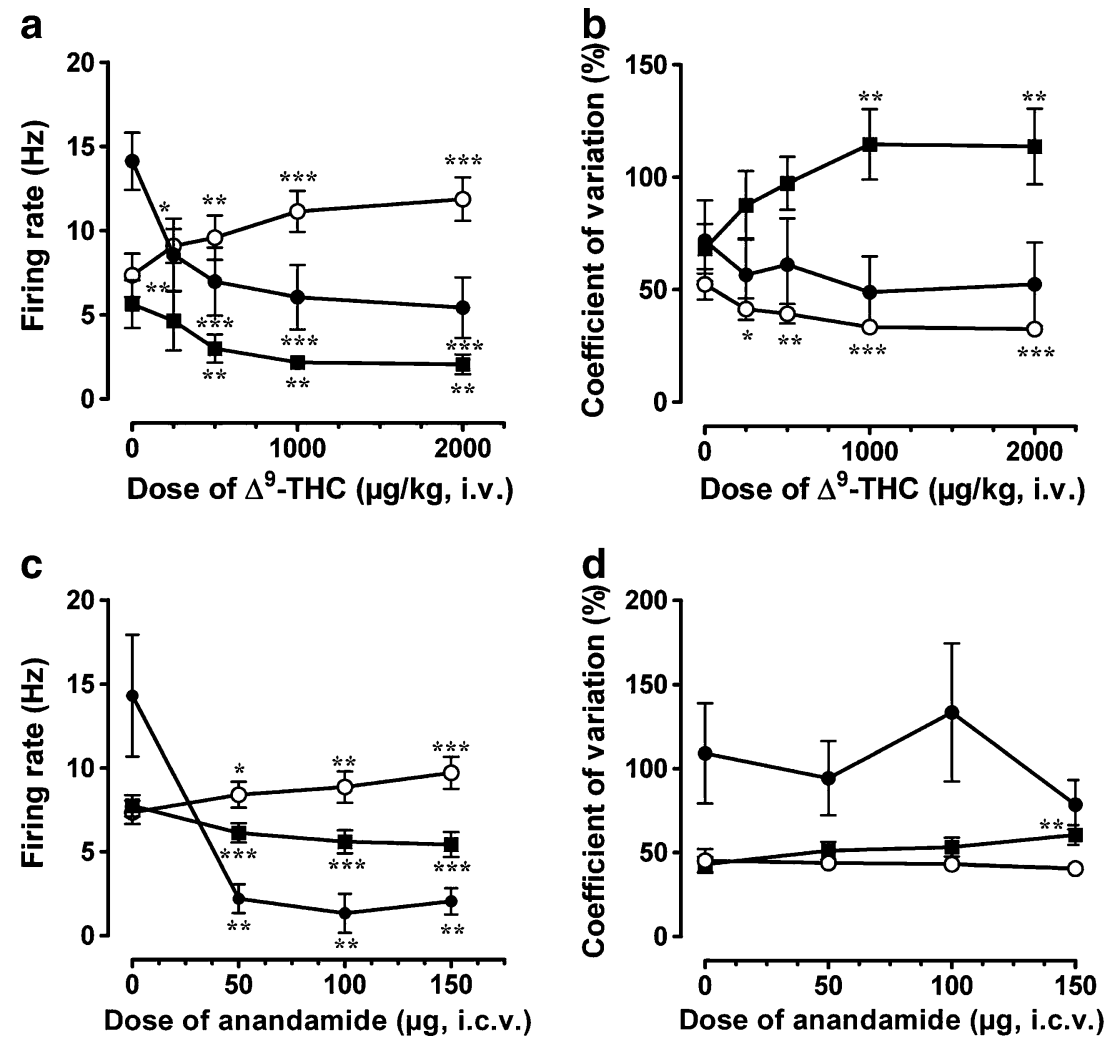

Fig. 3 Effects of cumulative doses of $\Delta^{9}$-THC and anandamide on STN neurons in intact and 6-OHDA-lesioned rats. a The mean firing rate and (b) the mean value of the coefficient of variation of STN neurons following $\Delta^{9}$-THC administration $(250-2,000 \mu \mathrm{g} / \mathrm{kg}$, i.v., doubling doses) in lesioned rats (black circle; $n=9$ ) and in intact rats, where two opposite effects were found: an increase (white circle; $n=$ 10) and a decrease in firing rate (black square; $n=5$ ). c The mean firing rate and (d) the mean value of the coefficient of variation of

counting in the SNpc was not necessary to verify lesion severity.

\section{Discussion}

The cannabinoid agonists $\Delta^{9}$-THC and anandamide are known to exert two opposite effects, i.e., inhibition and stimulation, on STN neurons through CB1 receptors located in the globus pallidus (GP) and cerebral cortex, respectively, by mechanisms involving GABA and excitatory amino acids (Morera-Herreras et al. 2010a, b). The present study further extends these results by showing that dopaminergic cell loss, induced by injection of 6-OHDA, abolishes or reverses the stimulatory effect of cannabinoid agonists on STN neurons, and enhances the effect of the endocannabinoid anandamide (see Table 1). These changes in cannabinoid response in lesioned rats can in principle be attributed to dopaminergic cell loss. Rotational behavior tests (involving apomorphine and/or amphetamine administration) were not performed in order to avoid pharmacological interactions.

STN neurons following anandamide administration (50-150 $\mu$ g, i.c.v.) in lesioned rats (black circle; $n=5$ ) and in intact rats, where two opposite effects were also observed: an increase (white circle; $n=8$ ) and a decrease in firing rate (black square; $n=8$ ). Data are expressed as mean \pm SEM. $* p<0.05 ; * * p<0.01 ; * * * p<0.001$ vs. corresponding basal value (one-way repeated measures ANOVA followed by the Student-Newman-Keuls test)

The classical model of basal ganglia functionality proposed by Alexander and Crutcher (1990) states that under normal conditions, the activity of the STN is regulated primarily by an inhibitory GABAergic projection from the external segment of the GP (Parent and Hazrati 1995) and by excitatory glutamatergic projections from multiple cortical areas (Fujimoto and Kita 1993; Maurice et al. 1998). According to this model, dopaminergic deficiency associated with the Parkinsonian state leads to reduced inhibition from the GP pathway, leading to disinhibition of the STN, resulting in its hyperactivity. The GP and the cerebral cortex are known to express moderate to high levels of CB1 receptor (Julian et al. 2003). Activation of these receptors inhibits the release of GABA and glutamate (Szabo et al. 2000; Gerdeman and Lovinger 2001; Wallmichrath and Szabo 2002), which can result in the stimulation or inhibition of STN, respectively. In 6OHDA-lesioned animals, the pallido-GABAergic influence on the STN is reduced (Bergman et al. 1998; Hassani et al. 1996). The absence of a stimulatory effect of cannabinoids in 6-OHDA-lesioned animals could therefore be understood in 
Fig. 4 Histological verification of the recording site in the subthalamic nucleus (STN). a Schematic illustration of the recording location of STN neurons. Image modified from Paxinos and Watson (1986), with permission from Elsevier. b Pontamine Sky Blue dots in Neutral Red-stained STN sections at different anatomical levels are homogenously distributed within the nucleus (the examples correspond to recorded neurons in 6-OHDAlesioned rats and in intact rats in which WIN 55,212-2 was administered). Scale bar, $40 \mu \mathrm{m}$ a

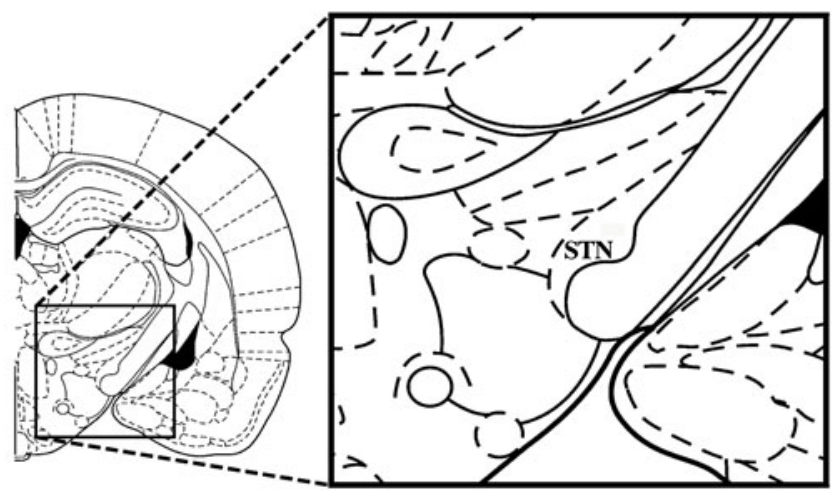

b

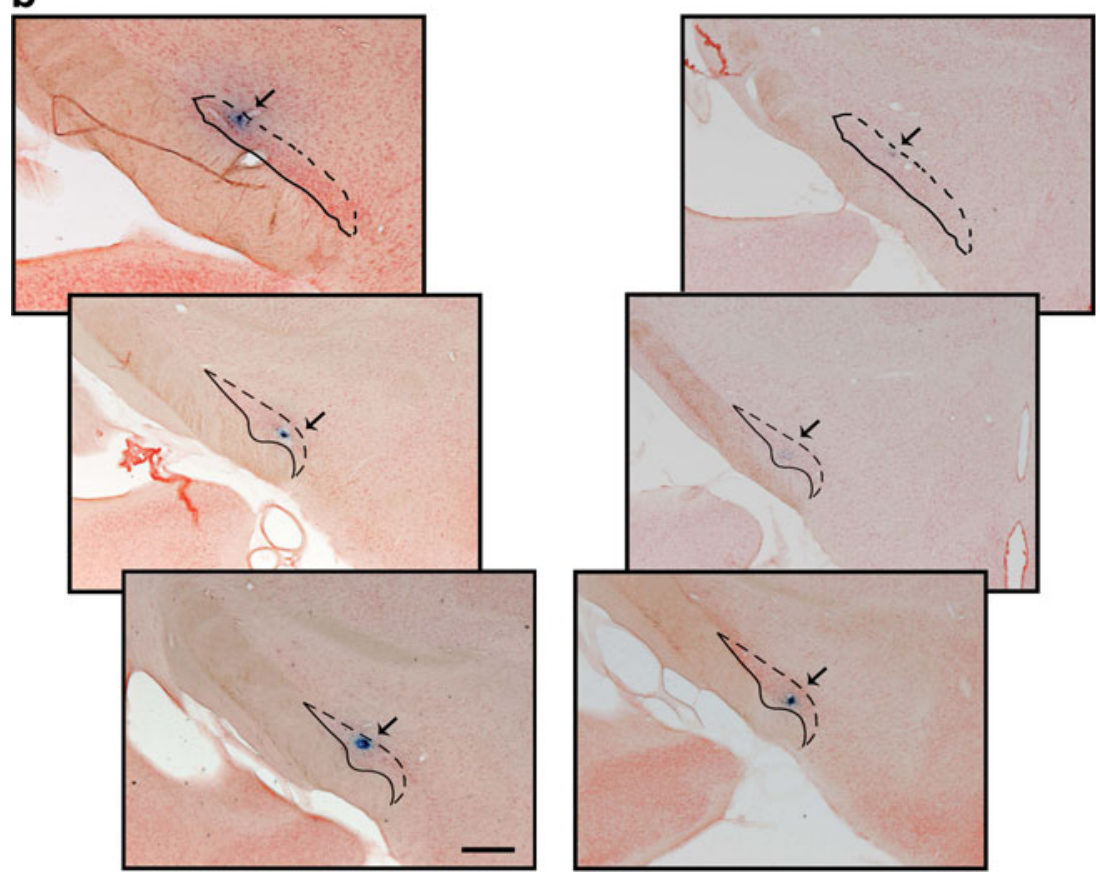

terms of the absence of GABAergic inhibition from the GP, and cannabinoid effects would be limited to their inhibition of glutamatergic neurotransmission (i.e., the presence of inhibition only), since the impact of the cortex on activity of the STN is even greater following depletion of dopamine (Magill et al. 2001). In line with this hypothesis, it has been suggested that endocannabinoid-mediated depression of indirect pathway synapses plays a critical role in the control of movement, since the endocannabinoid-mediated long-term depression of striato-pallidal medium spiny neurons (indirect pathway), which occurs in intact animals, is absent in PD animal models and is rescued by inhibitors of endocannabinoid degradation, which also reduce motor deficits (Kreitzer and Malenka 2007). Our results also corroborate those of Sañudo-Peña et al. (1998) who found that 6-OHDA-lesioned rats exhibited greater contralateral turning behavior in response to intranigral infusion of a cannabinoid agonist than intact rats and suggested that this could be due to the blockage of a hyperactive subthalamic input to the substantia nigra.

Another novel finding of the present study was that the synthetic cannabinoid agonist WIN 55,212-2 induced an exclusively stimulatory effect on STN neurons in intact rats, whereas the others cannabinoids used produced stimulation or inhibition. The stimulatory effect seems to be mediated by the same receptor, since the maximal stimulatory effect induced by WIN 55,212-2 or $\Delta^{9}$-THC was similar and higher than that due to anandamide (probably underestimated due to concomitant degradation by fatty acid amide hydrolase (Di Marzo et al. 1994)). In line with binding studies (Pertwee 1997), the results show that WIN 55,212-2 was more potent than the natural agonist, and in all cases, the effect of this synthetic cannabinoid was reversed by the CB1 cannabinoid receptor antagonist. The difference between the effect induced by WIN 55,212-2 and those previously shown with $\Delta^{9}$-THC 
Fig. 5 Representative tyrosine hydroxylase $(\mathrm{TH})$ immunostaining in the striatum $(\mathbf{a}, \mathbf{b})$ and substantia nigra $(\mathbf{c}, \mathbf{d})$ following 6-OHDA infusion into the right nigrostriatal pathway. In control rats (a, c), TH immunostaining was intense and comparable between both sides. In rats microinfused unilaterally with 6-OHDA into the right nigrostriatal pathway $(\mathbf{b}, \mathbf{d})$, a substantial loss of $\mathrm{TH}$ immunostaining was observed in each area (right side) compared with the contralateral side (left side)

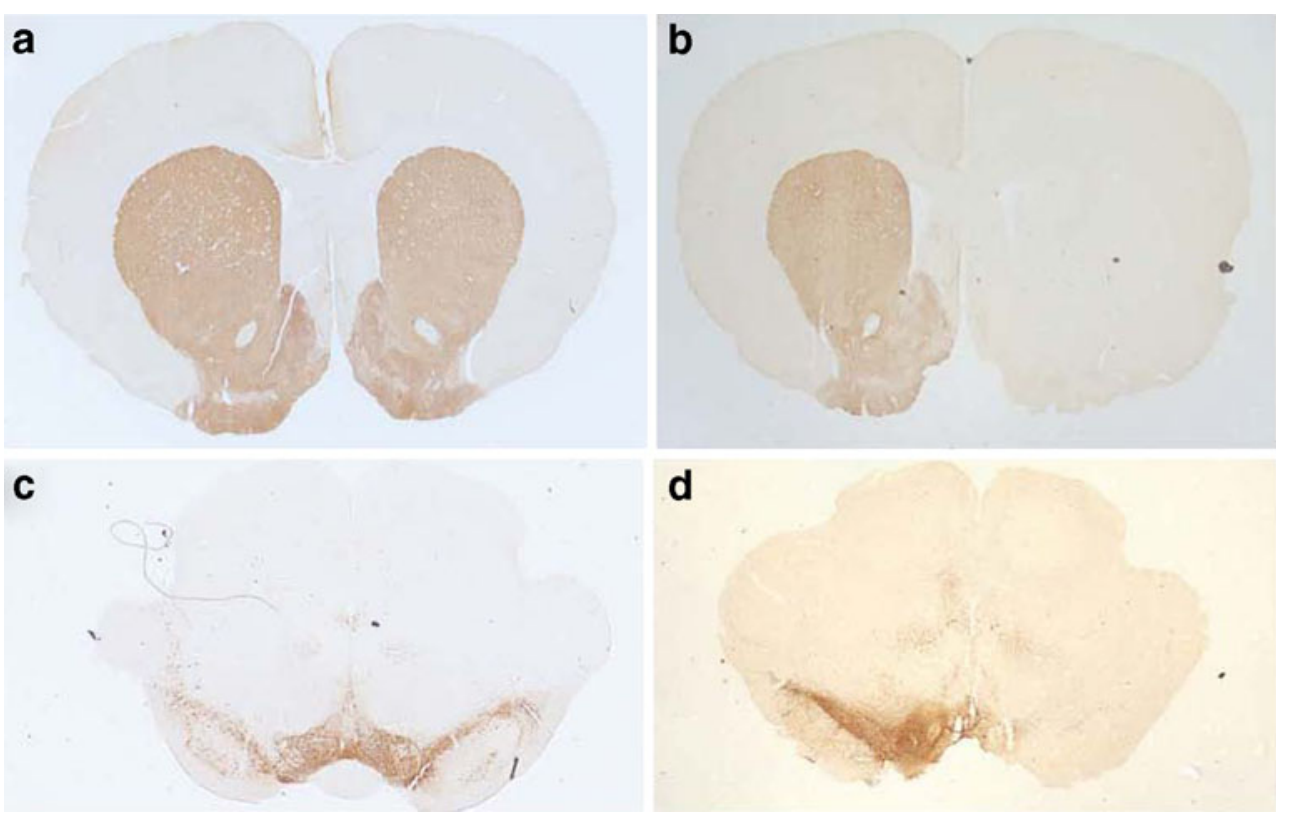

and anandamide may be due to the different sensitivity to WIN 55,212-2 of CB1 receptors mediating the inhibition of glutamate release or GABA release, as has been proposed by other authors (Hoffman and Lupica 2000; Hajos and Freund 2002; Hoffman et al. 2007). Corroborating this possibility, it has been reported that in the hippocampus, the receptor mediating the inhibition of glutamate release is less sensitive to WIN 55,212-2 than the CB1 receptor mediating the inhibition of GABA release (Hajos and Freund 2002).

Curiously, the inhibitory effect induced by anandamide was higher in 6-OHDA-lesioned rats than in intact rats. This could be due to overactivity of endocannabinoid transmission in the basal ganglia, which has been reported in 6-OHDA-lesioned or reserpine-treated rat models of PD. Thus, an increase in the tissue levels of endocannabinoids and $\mathrm{CB} 1$ receptors, as well as a decreased rate of endocannabinoid transport and degradation by the fatty acid amide hydrolase, has been found (Gubellini et al. 2002). Our data indicate that the sensitivity of CB1 receptors remains unaltered after lesion because the magnitude of the effects after administration of $\Delta^{9}$-THC or WIN 55,212-2 in intact and 6-OHDA-lesioned rats is similar. Therefore, the increased effect induced by anandamide in 6-OHDA-lesioned rats is more likely due to changes in the activity of FAAH. In keeping with this idea, we have previously shown that the blockage of endocannabinoid degradation by FAAH inhibition enhances the effects of anandamide on STN neurons in control rats (Morera-Herreras et al. 2010b).

The present results, corroborating the findings of many other studies, show that the STN is overactive in 6-OHDA lesioned rats (Bergman et al. 1994; Hassani et al. 1996; Vila et al. 2000; Ni et al. 2001; Magill et al. 2001). A decrease in STN hyperactivity is thought to underlie the efficacy of anti-Parkinsonian treatments. In fact, STN inactivation, by lesioning or implanting electrodes for deep stimulation, leads to an alleviation of the cardinal Parkinsonian features and of levodopa-induced dyskinesia in PD patients (Damier 2009). Several findings indicate that pharmacological modulation of the cannabinoid system may constitute a

Table 1 Summary of changes induced by cannabinoids on electrophysiological parameters of subthalamic neurons in control and 6-OH dopamine-lesioned (6OH-DA) rats

\begin{tabular}{|c|c|c|c|c|c|c|}
\hline & \multicolumn{2}{|c|}{ WIN 55,212-2 } & \multicolumn{2}{|l|}{$\Delta^{9}-\mathrm{THC}$} & \multicolumn{2}{|c|}{ Anandamide } \\
\hline & Control & 6-OHDA & Control & 6-OHDA & Control & 6-OHDA \\
\hline Firing rate & $\uparrow$ & $\downarrow$ & $\downarrow / \uparrow$ & $\downarrow$ & $\downarrow / \uparrow$ & $\downarrow \downarrow$ \\
\hline Coefficient of variation & $\downarrow$ & $=$ & $\uparrow / \downarrow$ & $=$ & $\uparrow /=$ & $=$ \\
\hline Burst firing & $\uparrow$ & $=$ & $=/ \uparrow$ & $=$ & $=/ \uparrow$ & $=$ \\
\hline
\end{tabular}

Cells were recorded for $180 \mathrm{~s}$ before and after drug administration

$\uparrow$ increase, $\downarrow$ decrease, = no change refer to changes in firing parameters after drug administration with respect to basal values 
new approach for the treatment of PD. However, results are still somewhat confusing. Thus, clinical trials have demonstrated that the cannabinoid receptor agonist nabilone significantly reduces L-dopa-induced dyskinesia in Parkinsonian patients (Sieradzan et al. 2001), whereas other clinical trials involving either agonists or antagonists have not found any effect on dyskinesias or parkinsonism (Frankel et al. 1990; Carroll et al. 2004; Mesnage et al. 2004). Results from animal studies are similarly confusing. For instance, it has been shown that cannabinoid agonists alleviate motor impairment seen in animal models of PD (Gilgun-Sherki et al. 2003; Kreitzer and Malenka 2007) and delay or reduce the incidence of L-dopa-induced dyskinesias (Fox et al. 2002; Morgese et al. 2007). Nevertheless, administration of a CB1 receptor antagonist was also found to lead to a decrease in motor disturbances associated with dopamine loss and L-dopa-induced dyskinesias (El-Banoua et al. 2004; Fernandez-Espejo et al. 2005; Gonzalez et al. 2006). The results of the present study may contribute to resolving these paradoxes, by showing that cannabinoids induce different effects on the STN depending on the integrity or degree of compromise of different components of the dopaminergic system.

Acknowledgements This study was supported by GIC07/143-IT436-10, SAF 2006-12340, and 2009-08664.

\section{Conflict of interest None.}

Open Access This article is distributed under the terms of the Creative Commons Attribution Noncommercial License which permits any noncommercial use, distribution, and reproduction in any medium, provided the original author(s) and source are credited.

\section{References}

Alexander GE, Crutcher MD (1990) Functional architecture of basal ganglia circuits: neural substrates of parallel processing. Trends Neurosci 13:266-271

Benazzouz A, Piallat B, Ni ZG, Koudsie A, Pollak P, Benabid AL (2000) Implication of the subthalamic nucleus in the pathophysiology and pathogenesis of Parkinson's disease. Cell Transplant 9:215-221

Bergman H, Wichmann T, Karmon B, DeLong MR (1994) The primate subthalamic nucleus II Neuronal activity in the MPTP model of Parkinsonism. J Neurophysiol 72:507-520

Bergman H, Feingold A, Nini A, Raz A, Slovin H (1998) Physiological aspects of information processing in the basal ganglia of normal and Parkinsonian primates. Trends Neurosci 21:32-38

Bilbao G, Ruiz-Ortega JA, Miguens N, Ulibarri I, Linazasoro G, Gomez-Urquijo S, Garibi J, Ugedo L (2006) Electrophysiological characterization of substantia nigra dopaminergic neurons in partially lesioned rats: effects of subthalamotomy and levodopa treatment. Brain Res 1084:175-184

Bisogno T, Berrendero F, Ambrosino G, Cebeira M, Ramos JA, Fernandez-Ruiz JJ, Di Marzo V (1999) Brain regional distribution of endocannabinoids: implications for their biosynthesis and biological function. Biochem Biophys Res Commun 256:377-380
Blandini F, Nappi G, Tassorelli C, Martignoni E (2000) Functional changes of the basal ganglia circuitry in Parkinson's disease. Prog Neurobiol 62:63-88

Breit S, Bouali-Benazzouz R, Popa RC, Gasser T, Benabid AL, Benazzouz A (2007) Effects of 6-hydroxydopamine-induced severe or partial lesion of the nigrostriatal pathway on the neuronal activity of pallido-subthalamic network in the rat. Exp Neurol 205:36-47

Brotchie JM (2003) CB1 cannabinoid receptor signalling in Parkinson's disease. Curr Opin Pharmacol 3:54-61

Burbaud P, Gross C, Benazzouz A, Coussemacq M, Bioula B (1995) Reduction of apomorphine-induced rotational behaviour by subthalamic lesion in 6-OHDA lesioned rats is associated with a normalization of firing rate and discharge pattern of pars reticulata neurons. Exp Brain Res 105:48-58

Carroll CB, Bain PG, Teare L, Liu X, Joint C, Wroath C, Parkin SG, Fox P, Wright D, Hobart J, Zajicek JP (2004) Cannabis for dyskinesia in Parkinson disease: a randomized double-blind crossover study. Neurology 12:1245-1250

Consroe P (1998) Brain cannabinoid systems as targets for the therapy of neurological disorders. Neurobiol Dis 5:534-551

Crawley JN, Corwin RL, Robinson JK, Felder CC, Devane WA, Axelrod J (1993) Anandamide, an endogenous ligand of the cannabinoid receptor, induces hypomotility and hypothermia in vivo in rodents. Pharmacol Biochem Behav 46:967-972

Damier P (2009) Drug-induced dyskinesias. Curr Opin Neurol 22:394-399

Di Marzo V, Fontana A, Cadas H, Schinelli S, Cimino G, Schwartz JC, Piomelli D (1994) Formation and inactivation of endogenous cannabinoid anandamide in central neurons. Nature 372:686691

Di Marzo V, Bifulco M, De Petrocellis L (2004) The endocannabinoid system and its therapeutic exploitation. Nat Rev Drug Discov 3:771-784

El-Banoua F, Caraballo I, Flores JA, Galan-Rodriguez B, FernandezEspejo E (2004) Effects on turning of microinjections into basal ganglia of $\mathrm{D}(1)$ and $\mathrm{D}(2)$ dopamine receptors agonists and the cannabinoid CB(1) antagonist SR141716A in a rat Parkinson's model. Neurobiol Dis 16:377-385

Fernandez-Espejo E, Caraballo I, de Fonseca FR, El Banoua F, Ferrer B, Flores JA, Galan-Rodriguez B (2005) Cannabinoid CB1 antagonists possess anti-Parkinsonian efficacy only in rats with very severe nigral lesion in experimental Parkinsonism. Neurobiol Dis 18:591-601

Fox SH, Henry B, Hill M, Crossman A, Brotchie J (2002) Stimulation of cannabinoid receptors reduces levodopa-induced dyskinesia in the MPTP-lesioned nonhuman primate model of Parkinson's disease. Mov Disord 17:1180-1187

Frankel JP, Hughes A, Lees AJ, Stern GM (1990) Marijuana for parkinsonian tremor. J Neurol Neurosurg Psychiatry $53: 436$

Fride E, Mechoulam R (1993) Pharmacological activity of the cannabinoid receptor agonist, anandamide, a brain constituent. Eur J Pharmacol 231:313-314

Fujimoto K, Kita H (1993) Response characteristics of subthalamic neurons to the stimulation of the sensorimotor cortex in the rat. Brain Res 609:185-192

Gerdeman G, Lovinger DM (2001) CB1 cannabinoid receptor inhibits synaptic release of glutamate in rat dorsolateral striatum. J Neurophysiol 85:468-471

Gilgun-Sherki Y, Melamed E, Mechoulam R, Offen D (2003) The CB1 cannabinoid receptor agonist, HU-210, reduces levodopainduced rotations in 6-hydroxydopamine-lesioned rats. Pharmacol Toxicol 93:66-70

Gonzalez S, Scorticati C, Garcia-Arencibia M, de Miguel R, Ramos JA, Fernandez-Ruiz J (2006) Effects of rimonabant, a selective 
cannabinoid CB1 receptor antagonist, in a rat model of Parkinson's disease. Brain Res 1073-1074:209-219

Gubellini P, Picconi B, Bari M, Battista N, Calabresi P, Centonze D, Bernardi G, Finazzi-Agro A, Maccarrone M (2002) Experimental parkinsonism alters endocannabinoid degradation: implications for striatal glutamatergic transmission. J Neurosci 22:6900-6907

Hajos N, Freund TF (2002) Distinct cannabinoid sensitive receptors regulate hippocampal excitation and inhibition. Chem Phys Lipids 121:73-82

Hamani C, Saint-Cyr JA, Fraser J, Kaplitt M, Lozano AM (2004) The subthalamic nucleus in the context of movement disorders. Brain 127:4-20

Hassani OK, Mouroux M, Feger J (1996) Increased subthalamic neuronal activity after nigral dopaminergic lesion independent of disinhibition via the globus pallidus. Neuroscience 72:105115

Herkenham M, Lynn AB, de Costa BR, Richfield EK (1991) Neuronal localization of cannabinoid receptors in the basal ganglia of the rat. Brain Res 547:267-274

Hoffman AF, Lupica CR (2000) Mechanisms of cannabinoid inhibition of GABA(A) synaptic transmission in the hippocampus. J Neurosci 20:2470-2479

Hoffman AF, Oz M, Yang R, Lichtman AH, Lupica CR (2007) Opposing actions of chronic Delta9-tetrahydrocannabinol and cannabinoid antagonists on hippocampal long-term potentiation. Learn Mem 14:63-74

Hohmann AG, Herkenham M (2000) Localization of cannabinoid $\mathrm{CB}(1)$ receptor mRNA in neuronal subpopulations of rat striatum: a double-label in situ hybridization study. Synapse $37: 71-80$

Hollerman JR, Grace AA (1992) Subthalamic nucleus cell firing in the 6-OHDA-treated rat: basal activity and response to haloperidol. Brain Res 590:291-299

Julian MD, Martin AB, Cuellar B, Rodriguez De Fonseca F, Navarro M, Moratalla R, Garcia-Segura LM (2003) Neuroanatomical relationship between type 1 cannabinoid receptors and dopaminergic systems in the rat basal ganglia. Neuroscience 119:309-318

Kaneoke Y, Vitek JL (1996) Burst and oscillation as disparate neuronal properties. J Neurosci Methods 68:211-223

Kreitzer AC, Malenka RC (2007) Endocannabinoid-mediated rescue of striatal LTD and motor deficits in Parkinson's disease models. Nature 8:643-647

Lastres-Becker I, Cebeira M, de Ceballos ML, Zeng BY, Jenner P, Ramos JA, Fernandez-Ruiz JJ (2001) Increased cannabinoid CB1 receptor binding and activation of GTP-binding proteins in the basal ganglia of patients with Parkinson's syndrome and of MPTP-treated marmosets. Eur J Neurosci 14:1827-1832

Levy R, Hutchison WD, Lozano AM, Dostrovsky JO (2000) Highfrequency synchronization of neuronal activity in the subthalamic nucleus of Parkinsonian patients with limb tremor. J Neurosci 20:7766-7775

Limousin P, Pollak P, Benazzouz A, Hoffmann D, Broussolle E, Perret JE, Benabid AL (1995) Bilateral subthalamic nucleus stimulation for severe Parkinson's disease. Mov Disord 10:672-674

Maccarrone M, Gubellini P, Bari M, Picconi B, Battista N, Centonze D, Bernardi G, Finazzi-Agro A, Calabresi P (2003) Levodopa treatment reverses endocannabinoid system abnormalities in experimental Parkinsonism. J Neurochem 85:1018-1025

Mackie K (2005) Distribution of cannabinoid receptors in the central and peripheral nervous system. Handb Exp Pharmacol 168:299-325

Magariños-Ascone CM, Figueiras-Mendez R, Riva-Meana C, Cordoba-Fernandez A (2000) Subthalamic neuron activity related to tremor and movement in Parkinson's disease. Eur J Neurosci $12: 2597-2607$
Magill PJ, Bolam JP, Bevan MD (2001) Dopamine regulates the impact of the cerebral cortex on the subthalamic nucleus-globus pallidus network. Neuroscience 106:313-330

Maurice N, Deniau JM, Glowinski J, Thierry AM (1998) Relationships between the prefrontal cortex and the basal ganglia in the rat: physiology of the corticosubthalamic circuits. J Neurosci 18:9539-9546

Mesnage V, Houeto JL, Bonnet AM, Clavier I, Arnulf I, Cattelin F, Le Fur G, Damier P, Welter ML, Agid Y (2004) Neurokinin B, neurotensin, and cannabinoid receptor antagonists and Parkinson disease. Clin Neuropharmacol 27:108-110

Morera-Herreras T, Ruiz-Ortega JA, Ugedo L (2010a) Two opposite effects of delta(9)-tetrahydrocannabinol on subthalamic nucleus neuron activity: involvement of GABAergic and glutamatergic neurotransmission. Synapse 64:20-29

Morera-Herreras T, Ruiz-Ortega JA, Taupignon A, Baufreton J, Manuel I, Rodriguez-Puertas R, Ugedo L (2010b) Regulation of subthalamic neuron activity by endocannabinoids. Synapse 64:682-698

Morgese MG, Cassano T, Cuomo V, Giuffrida A (2007) Antidyskinetic effects of cannabinoids in a rat model of Parkinson's disease: role of $\mathrm{CB}(1)$ and TRPV1 receptors. Exp Neurol 208:110-119

Ni ZG, Bouali-Benazzouz R, Gao DM, Benabid AL, Benazzouz A (2001) Time-course of changes in firing rates and firing patterns of subthalamic nucleus neuronal activity after 6-OHDA-induced dopamine depletion in rats. Brain Res 899:142-147

Pacher P, Batkai S, Kunos G (2006) The endocannabinoid system as an emerging target of pharmacotherapy. Pharmacol Rev 58:389462

Parent A, Hazrati LN (1995) Functional anatomy of the basal ganglia. I. The cortico-basal ganglia-thalamo-cortical loop. Brain Res Brain Res Rev 20:91-127

Paxinos G, Watson C (1986) The rat brain in stereotaxic coordinates, 2nd edn. Academic, Orlando

Pertwee RG (1997) Pharmacology of cannabinoid $\mathrm{CB}_{1}$ and $\mathrm{CB}_{2}$ receptors. Pharmacol Ther 72:129-180

Piallat B, Benazzouz A, Benabid AL (1999) Neuroprotective effect of chronic inactivation of the subthalamic nucleus in a rat model of Parkinson's disease. J Neural Transm Suppl 55:71-77

Pisani A, Fezza F, Galati S, Battista N, Napolitano S, Finazzi-Agro A, Bernardi G, Brusa L, Pierantozzi M, Stanzione P, Maccarrone M (2005) High endogenous cannabinoid levels in the cerebrospinal fluid of untreated Parkinson's disease patients. Ann Neurol 57:777-779

Romero J, Berrendero F, Perez-Rosado A, Manzanares J, Rojo A, Fernandez-Ruiz JJ, de Yebenes JG, Ramos JA (2000) Unilateral 6-hydroxydopamine lesions of nigrostriatal dopaminergic neurons increased CB1 receptor mRNA levels in the caudate-putamen. Life Sci 66:485-494

Romero J, Lastres-Becker I, de Miguel R, Berrendero F, Ramos JA, Fernandez-Ruiz J (2002) The endogenous cannabinoid system and the basal ganglia biochemical, pharmacological, and therapeutic aspects. Pharmacol Ther 95:137-152

Sañudo-Peña MC, Patrick SL, Khen S, Patrick RL, Tsou K, Walker JM (1998) Cannabinoid effects in basal ganglia in a rat model of Parkinson's disease. Neurosci Lett 248:171-174

Sieradzan KA, Fox SH, Hill M, Dick JP, Crossman AR, Brotchie JM (2001) Cannabinoids reduce levodopa-induced dyskinesia in Parkinson's disease: a pilot study. Neurology 11:2108-2111

Silverdale MA, McGuire S, McInnes A, Crossman AR, Brotchie JM (2001) Striatal cannabinoid CB1 receptor mRNA expression is decreased in the reserpine-treated rat model of Parkinson's disease. Exp Neurol 169:400-406

Smith PB, Compton DR, Welch SP, Razdan RK, Mechoulam R, Martin BR (1994) The pharmacological activity of anandamide, a 
putative endogenous cannabinoid, in mice. J Pharmacol Exp Ther 270:219-227

Szabo B, Wallmichrath I, Mathonia P, Pfreundtner C (2000) Cannabinoids inhibit excitatory neurotransmission in the substantia nigra pars reticulate. Neuroscience 97:89-97

Vila M, Perier C, Feger J, Yelnik J, Faucheux B, Ruberg M, RaismanVozari R, Agid Y, Hirsch EC (2000) Evolution of changes in neuronal activity in the subthalamic nucleus of rats with unilateral lesion of the substantia nigra assessed by metabolic and electrophysiological measurements. Eur J Neurosci 12:337344

Wallmichrath I, Szabo B (2002) Cannabinoids inhibit striatonigral GABAergic neurotransmission in the mouse. Neuroscience 113:671-682

Zeng BY, Dass B, Owen A, Rose S, Cannizzaro C, Tel BC, Jenner P (1999) Chronic L-DOPA treatment increases striatal cannabinoid CB1 receptor mRNA expression in 6-hydroxydopamine-lesioned rats. Neurosci Lett 276:71-74 